\title{
DESMISTIFICAR O PROCESSO (IN)CONSTITUCIONAL DAS BASES EDUCACIONAIS BRASILEIRAS
}

\author{
Adriano Carvalho Viana*
}

Resumo: A proposta deste artigo é fazer uma análise da Educação Básica Brasileira, bem como constar normas e direitos fundamentais que devem ser seguidos. São ressaltados também o Estatuto da Criança e do Adolescente (ECA) e a Constituição Federal Brasileira. Como objetivo, buscou-se evidenciar o ensino básico (pré-escola e sua gratuidade para com a sociedade). Em linhas gerais, o presente trabalho visa informar o leitor pelo viés da Constituição Federal Brasileira e os Direitos Fundamentais, além de fornecer dados do INEP em relação à Educação Básica no ano de 2017.

Palavras-chave: Constituição Federal. Estatuto da Criança e do Adolescente. Educação Básica. Direitos Fundamentais.

\begin{abstract}
The proposal of this article is to make an analysis of the Brazilian Basic Education, as well as to establish norms and fundamental rights that must be followed. It is also highlighted the Statute of the Child and Adolescent (ECA) and the Brazilian Federal Constitution. The objective was to highlight Basic Education (pre-school and its gratuitousness with society). In general terms, this paper aim is to inform the reader through the Brazilian Federal Constitution and Fundamental Rights and, in addition, to provide INEP data regarding Basic Education in 2017.
\end{abstract}

Keywords: Brazilian Federal Constitution. Statute of the Child and Adolescent. Basic Education. Fundamental Rights.

\section{Introdução}

\footnotetext{
*Mestrando em Letras - Pontifícia Universidade Federal do Maranhão. Graduado em Filosofia pelo Centro
} Universitário Assunção - UNIFAI. Graduando em Direito pela Faculdade Santa Terezinha - CEST. 
O que deve fazer um pai que quer ingressar o seu filho na base educacional brasileira? Quais os trâmites legais para matriculá-lo? Qual é a responsabilidade do Município? Esta pesquisa busca responder a essas questões, entre outras, discorrendo sobre as formas consideradas legais e ilegais da educação brasileira, baseado numa vasta literatura jurídica referenciada principalmente na Constituição Federal e no Estatuto da Criança e do Adolescente.

A prática da educação, comum em toda a humanidade, sabidamente ocorre desde os tempos mais remotos, sendo inclusive objeto de relatos bíblicos, a exemplo dos ensinamentos de Jesus aos seus discípulos, por meio da Palavra $(\log O)^{1}{ }^{1}$. No sentido mais latu da palavra, a educação sempre foi manuseada de forma a ser ato ou processo de educar, procedimento metódico de uma faculdade, de um sentido, de um órgão; sua finalidade, enfim, sempre foi metodológica.

No Brasil, a educação se faz presente desde o período colonial e inicialmente esteve ligada à evangelização, por influência da Igreja Católica, em que os índios eram catequizados/educados pelos padres jesuítas, informalmente e estes forneciam os bens das terras tupiniquins em troca das aulas catequéticas.

Ao longo da história, o processo da educação brasileira ganhou materialidade e rigidez. Buscou-se exibir de forma sistematizada o processo de Educação com ênfase na Constituição Federal, enfatizando as condições necessárias para os trâmites legais da educação no Estado Democrático de Direito, que é o Brasil, destacando a existência da Lei de Diretrizes e Bases da Educação Nacional (LDB) e o processo da educação e suas garantias legais.

Por tratar diretamente das relações de ensino da criança e do adolescente, recorremos ao Estatuto da Criança e à extensa gama de sentimentos controversos gerados por uma educação frágil e fragmentada.

Metodologicamente analisaremos o contexto histórico da Educação brasileira em suas construções, e paulatinamente nos debruçaremos sobre a Constituição Federal com sua lei de obrigatoriedade da Lei de Educação básica para crianças, o papel dos Direitos Humanos

\footnotetext{
${ }^{1}$ RATZINGER explica que o termo logos significa tanto "palavra/ Verbo" quanto "razão", e isso indica que uma das características mais importantes da fé cristã é o fato de ela ser razoável e acessível à razão.
} 
Fundamentais e, por fim, traremos como conclusão embasamentos para os caminhos de uma educação justa e igualitária.

Desmistificar a educação é um caminho que perpassa pela mudança na herança cultural dos costumes da informalidade, pela prática dos trâmites legais, pelos quais devem seguir formalmente aqueles que possuam a real intenção de garantir aos educandos a totalidade dos direitos e garantias.

\section{O contexto histórico do processo da educação brasileira pelo viés das Constituições}

Situar a educação no Brasil, mais precisamente a educação dos índios, é indissociável da história da Companhia de Jesus (Jesuítas). As negociações de Dom João III, o Piedoso, junto a esta ordem missionária católica podem ser consideradas um marco, pois através delas os índios foram submetidos à chamada "catequese", promovida pelos missionários jesuítas que vinham ao novo "País" difundir a crença cristã entre os nativos, tendo como grande expoente dessa congregação o padre Manuel da Nóbrega.

Em 1759, historicamente, houve a expulsão dos jesuítas (reformas pombalinas), passando assim a ser instituído o ensino laico e público através das Aulas Régias. Em 1822, havia propostas para a Educação na Assembleia Constituinte (inspiradas nos ideais da Revolução Francesa), porém só na Constituição de 1824 é que vieram à tona o princípio da liberdade de ensino, sem restrições, e a intenção de "instrução gratuita a todos os cidadãos".

Em 15de outubro de 1827, foi aprovada a primeira lei sobre o Ensino Elementar, e a mesma vigoraria até 1946. Esta lei determinou a criação de “[...] escolas de primeiras letras em todas as cidades, vilas e lugarejos [...]" (artigo $\left.1^{\circ}\right)$ e "[...] escolas de meninas nas cidades e vilas mais populosas [...]" (artigo XI). Por inúmeros motivos, essas leis fracassaram e em 1834 se deu o Ato Adicional que emendou a Constituição, gerando a reforma que deixava o ensino elementar, secundário e de formação dos professores a cargo das províncias, enquanto o poder central cuidaria do Ensino Superior. Dessa maneira, foi criado o famoso Imperial Colégio de Pedro II, em 1837, (e) os primeiros liceus provinciais.

Após 80 anos, os Jesuítas retornaram e fundaram o Colégio São Luís, localizado em Itu em 1867 e transferido para São Paulo em 1919. Daremos um salto para o fim do Estado Novo, momento em que surge a Constituição de 1946, que trouxe dispositivos 
dirigidos à educação, como a gratuidade para o Ensino primário e a manutenção da mesma na sequencia dos estudos; e em 1948, surgiu a discussão para uma Lei de Diretrizes Básicas (LDB), a partir da proposta do deputado Clemente Mariani. A educação, porém, só mereceu destaque na Constituição de 1988, com o Ato das Disposições Constitucionais Transitórias (ADCT), modificado pela Emenda Constitucional 14/1996.

\title{
2. (In)constitucionalidade do direito a educação
}

A educação é âmago para o desenvolvimento de uma sociedade. Sua base deve ser sólida e concisa. No Brasil, o Estado tem a obrigação de oferecer educação formal para todas as crianças e adolescentes, porém a República Federativa do Brasil, formada pela união indissolúvel dos Estados e Municípios e do Distrito Federal, constitui-se em Estado Democrático de Direito, e as responsabilidades pelos mais diversos serviços públicos acabam sendo distribuídos entre essas unidades.

\begin{abstract}
A incumbência para fornecer a educação de base coube ao Município, ou seja, creches (até 3 anos), pré-escolas (educação infantil; 4 e 5 anos) e o ensino fundamental (7 a 14 anos) são de competência Municipal. No entanto, a Lei $\mathrm{n}^{\circ}$ 12.796, de 4 de abril de 2013, posteriormente revogada pela Lei $\mathrm{n}^{\circ} 13.306$, de 2016 têm no seu dispositivo legal o seguinte texto: "A lei dispõe que ela entre em vigor na data da sua publicação, [e por isso] os pais já têm o dever de procurar vagas para seus filhos a partir dos 4 anos na educação básica [a partir desta sexta]" no diário oficial da União e existem várias decisões do STF nesse sentido, como é o caso do RE 956475, Rel. Min. Celso de Mello, julgado em 12/05/2016 (Info 826).
\end{abstract}

A observação interpretativa da lei é que passado o período de vacatio legis, ou seja, (Vacância da Lei), a mesma entraria em vigor, e entrou, trazendo assim para pais e entes públicos a responsabilidade por garantir a educação dessas crianças. Os gestores públicos teriam de cumpri-la desde então, sob pena de se considerar crime de responsabilidade, no caso de negligência com sua implementação, conforme já dizia o artigo $5^{\circ}$ (parágrafo) $\S 4$, da Lei 9.394/96(LDB).

A Educação de base se tornou, então, um emaranhado do processo formativo, tendo, pois, uma ressalva da Lei que a tornou categórica. "A educação infantil”, primeira etapa da educação básica, teve a finalidade do desenvolvimento integral da Criança de até 5 anos, que outrora era fragmentado, e essa mesma criança que estava fora do ambiente escolar 
era integrada opcionalmente, retirando do Governo a responsabilidade de fornecer e de ter custos com a educação infantil, fragmentando o processo educacional.

O Estatuto da Criança e do Adolescente (ECA), por sua vez, estabelece nos artigos 54 (cinquenta e quatro) e 55 (cinquenta e cinco) alguns deveres do Estado, e nos deteremos nos incisos I e IV e nos (parágrafos) $\S 2^{\circ}$ e $\S 3^{\circ}$, do inciso VII, e no art. 55, principalmente. Veremos minuciosamente cada pormenor das leis que embasam o ensino obrigatório na educação básica:

\footnotetext{
Art. 54. É dever do Estado assegurar à criança e ao adolescente:

Ensino fundamental, obrigatório e gratuito, inclusive para os que a ele não tiverem acesso na idade própria;

IV- atendimento em creche e pré-escola às crianças de zero a cinco anos de idade; (Redação dada pela Lei nº 13.306, de 2016).

$\S 2^{\circ} \mathrm{O}$ não oferecimento do ensino obrigatório pelo poder público ou sua oferta irregular importa responsabilidade da autoridade competente.

$\S 3^{\circ}$ Compete ao poder público recensear os educandos no ensino fundamental, fazer-lhes a chamada e zelar, junto aos pais ou responsável, pela frequência à escola. Art. 55. Os pais ou responsável têm a obrigação de matricular seus filhos ou pupilos na rede regular de ensino.
}

O que esses artigos ressalvam são algumas das garantias adquiridas pela criança na Educação básica. Porém, nosso tema é desmistificar o processo educacional e demonstrar que não é só única e exclusivamente dever do Estado garantir a educação, conforme os Direitos Humanos Fundamentais, cabendo à família a responsabilidade de promovê-la. Assim, faz-se necessário analisar o todo.

\section{Os direitos humanos fundamentais e o direito social à educação}

Um pequeno preâmbulo faz-se necessário sobre os direitos fundamentais, que guiam a Constituição Federal, principalmente nos seus artigos mais importantes. Existe a limitação do poder estatal, e os direitos fundamentais ganham força e forma e dividem-se para fins didáticos em três gerações.

A primeira geração fundamenta-se na primeira Constituição Federal escrita no mundo, que foi a Norte-Americana. Havia a ideia de república presidencialista e a repartição dos poderes do federalismo, no modelo de Commom Law, ou seja, uma Constituição guiada pelos Costumes, e que têm como base a suprema corte, por sua vez indissolúvel. Alguns 
direitos foram assegurados tais como: ir e vir, vida e propriedade. Rege-se pelo Estado de Direito Absolutista e Liberal.

A segunda geração dos direitos fundamentais, a qual nos norteará nesta análise, trata dos direitos à igualdade e salienta a igualdade material e efetiva, que provém do Estado social com políticas públicas. O Estado tem a obrigação de fazer algo ou fornecer algo, bem como: educação, saúde, segurança, distribuição de renda, ou seja, um Estado Social e intervencionista.

Por sua vez, a terceira geração, a título de informação, embasa-se no Estado Democrático de Direito, com princípios como a dignidade da pessoa humana, participação social nas decisões políticas e respeito às minorias e também os direitos difusos como ao meio ambiente.

A Constituição Federal traz consigo os Direitos e Garantias Fundamentais. Conforme citado anteriormente, nos deteremos nos direitos da segunda geração, que tratam da Igualdade. No capítulo I - Dos Direitos e Deveres Individuais e Coletivos, o Artigo $5^{\circ}$ diz: “Todos são iguais perante a lei, sem distinção de qualquer natureza garantindo-se aos brasileiros e aos estrangeiros residentes no País a inviolabilidade do direito à vida, à igualdade, à segurança e à propriedade, nos termos seguintes" (BRASIL, 1988, p.5).

É importante verificar que o Direito Social à Educação conforme o artigo $6^{\circ}$ da Constituição Federal de 1988, diz no seu caput: "São direitos sociais a educação, a saúde, a alimentação, o trabalho, a moradia, o transporte, o lazer, a segurança, a previdência social, a proteção à maternidade e à infância, a assistência aos desamparados, na forma desta Constituição" (BRASIL, 1988, p.6).

Ao tratarmos de Igualdade, aplica-se o princípio da Isonomia, também conhecido como princípio da igualdade, um símbolo da democracia, pois indica um tratamento justo para os cidadãos e é muito utilizado pela jurisprudênciazdos Tribunais Federais, pelo qual se deve tratar todos os iguais de maneira igual e os diferentes de modo diferente.

No entanto, há contradições na própria letra da Constituição Federal. A premissa é que o Art. $5^{\circ}$ fala sobre Igualdade, os Tribunais Federais, se norteia pelo princípio da Isonomia e o direito à Educação pode não ser assegurado pelo Estado. Logo, observa-se incompletude dentro dos próprios trâmites legais.

\footnotetext{
${ }^{2}$ Decisões reiteradas de quaisquer Tribunais Federais
} 
Mais à frente, o artigo 205 da Constituição Federal salienta no seu caput o seguinte texto: "A educação, direito de todos e dever do Estado e da Família, será promovida e incentivada com a colaboração da sociedade, visando ao pleno desenvolvimento da pessoa, seu preparo para o exercício da cidadania e sua qualificação para o trabalho".

Especificamente em relação às crianças e aos adolescentes, tanto a Constituição Federal no seu artigo 227, como o Estatuto da Criança e do Adolescente artigo $4^{\circ}$ da Lei 8.069/90, preveem que a família, a sociedade e o Estado devem assegurar os direitos fundamentais desses sujeitos, o que inclui a educação como absoluta prioridade.

Não obstante, como cobrar do Estado uma educação básica de qualidade? Eis, a pergunta e como resposta, temos as redes municipais de ensino totalmente fragmentadas. Uma vez que falamos em direitos fundamentais assegurados e garantidos e em competência do Estado, logo este órgão deveria se responsabilizar em promover políticas públicas que forneçam educação de qualidade.

E para responder à pergunta no final do tópico dois, vemos que na prática há uma precariedade. Existe educação básica oferecida pelo município, ela não é de boa qualidade e nem sempre os alunos encontram vaga onde querem, mas, supostamente, todas as crianças estão na escola do ensino básico pela sabida existência de verbas desviadas, secretarias de Educação com funcionários fantasmas e demais falhas demonstrando o descaso total no que tange ao processo formativo de Crianças e Adolescentes. Os Direitos Fundamentais não são colocados em prática e muito menos a Constituição Federal, norma superior do Estado Democrático de Direito. O texto é lindo, regimentar, normativo e muito contundente, porém, não é aplicável e muito menos obedecido.

\section{Metodologia e dados do Inep}

Metodologicamente, iremos neste tópico apresentar o que é o Censo Escolar da Educação Básica, depois serão apresentados os dados das escolas que os brasileiros frequentam, porém nos voltaremos para a pré-escola como base das fontes do Inep (Instituto Nacional de Estudos e Pesquisas Educacionais Anísio Teixeira) e, por fim, uma pequena conclusão acerca dos dados do Censo Escolar e quais caminhos são necessários para se chegar a uma educação de qualidade. 


\subsection{Censo Escolar da Educação Básica e Índice de Desenvolvimento da Educação Básica}

O que é o Censo Escolar da Educação Básica? É uma pesquisa realizada anualmente pelo Instituto Nacional de Estudos e Pesquisas Educacionais Anísio Teixeira (INEP) em articulação com as Secretarias Estaduais de Educação das 27 unidades da federação, sendo obrigatória aos estabelecimentos públicos e privados de educação básica, conforme determina o art. $4^{\circ}$ do Decreto $n^{\circ} 6.425 / 2008$.

Trata-se de um amplo e relevante levantamento sistemático sobre a educação básica no País. Os dados coletados constituem a mais completa fonte de informações utilizadas pelo Ministério da Educação (MEC). Tudo isto se faz necessário para a formulação, monitoramento e avaliação de políticas públicas, bem como para a definição de programas e de critérios para a atuação supletiva do MEC junto às escolas, aos estados e aos municípios.

Também subsidia o cálculo de vários indicadores, dentre eles o Índice de Desenvolvimento da Educação Básica (IDEB) e outros que possibilitam contextualizar os resultados das avaliações e monitorar a trajetória dos estudantes em seu ingresso na escola.

Os dados aqui apresentados foram retirados do site do INEP e as porcentagens foram geradas a partir dos resultados apresentados pelas escolas que os brasileiros frequentam. Seguem abaixo os dados das pré-escolas da Federação brasileira, segundo fontes do INEP.

O País conta com 186,1 mil escolas de Educação Básica. A maior rede de educação básica do País está sob a responsabilidade dos municípios, concentrando cerca de 2/3 das escolas (114,7mil); a participação das escolas da rede privada passou de 21,1\% em 2016 para 21,5\% em 2017. O Percentual de escolas de educação básica por dependência administrativa no Brasil 2017. 50.5\% das escolas de educação básica possuem biblioteca e/ou sala de leitura (esse percentual é de 53,7\% para as que ofertam ensino fundamental e de $88,3 \%$ no ensino médio); o percentual de escolas de educação básica com biblioteca e/ou sala de leitura por município 2017 $33,9 \%$ das escolas brasileiras encontram-se na zona rural; o percentual de escolas de educação básica por localização. 15,9\% das escolas têm mais de 500 matrículas e 23,8\% das escolas têm até 50 matrículas; o acesso à internet está amplamente disponível nas escolas das regiões Sul, Sudeste e Centro-Oeste; o percentual de escolas de educação básica com acesso à internet por município 2017. 7,2\% das escolas possuem um único docente - $\mathrm{O}$ indica que essa característica está relacionada às escolas da zona rural. Visualização conjunta do percentual de escolas na zona rural e percentual de escolas por Unidade da 
Federação. Federal- 0,4\%, Estadual-16,5\%, Municipal-61,7\%, Privada-21,5\%. (INEP, 2017, p.6). Há 105,3 mil unidades com pré-escola no Brasil, 57,4\% estão na zona urbana, $72,8 \%$ são municipais e $26,3 \%$ são privadas; a União e os estados têm participação de $1 \%$ nesta etapa de ensino; das 44,9 mil escolas rurais, $98,0 \%$ estão sob a responsabilidade dos municípios. Apenas 13,4\% funcionam em estabelecimentos de uma sala de aula, dessas, $95,1 \%$ estão na zona rural; 70,6\% das escolas que oferecem pré-escola possuem até 50 matrículas nesse segmento $41,6 \%$ dispõem de parque infantil; $\mathrm{Na}$ zona rural, 7,4\% das escolas não possuem energia elétrica, $12,7 \%$ não têm esgoto sanitário e $11,6 \%$ não têm abastecimento de água. Na zona urbana, apenas seis escolas não possuem energia elétrica, $0,2 \%$ não têm esgoto sanitário e $0,2 \%$ não têm abastecimento de água; $42,8 \%$ das pré-escolas têm banheiro adequado à educação infantil $47,4 \%$ desses estabelecimentos de ensino têm sala de professores e 55,6\% têm secretaria; $29 \%$ das pré-escolas têm banheiro adequado a alunos com deficiência ou mobilidade reduzida 23,3\% dessas escolas têm dependências e vias adequadas a alunos com deficiência ou mobilidade reduzida; pátio coberto, presente em 45,3\% das escolas, área verde, 29,4\%, e quadra de esporte coberta, 15,9\%,completam a lista de dependências disponíveis nas escolas da primeira etapa de escolaridade obrigatória no Brasil.(INEP, 2017, p.7).

Ambas as citações com dados do Inep revelam um descaso para com a Educação básica, ou seja, o Município incumbe-se de cuidar da educação e de fornecê-la para todas as crianças, no entanto, há uma debilidade nos recursos físicos e humanos, falta de manutenção, escolas em situação precárias e atrasos nos salários de professores. As leis de políticas públicas são aplicadas, porém não seguidas. O que fazer? Retornamos ao ponto inicial deste artigo.

Cabe aqui uma crítica dura ao Governo, ao Estado e a todos os representantes públicos, porém é de suma importância constatar que os cidadãos que possuem poder aquisitivo não se preocupam com a Educação dos que não têm e não podem. Aqueles posam de bons cidadãos e pagadores de seus impostos ingressam seus filhos em escolas privadas para que no futuro eles ingressem em faculdades públicas, o inverso do avesso.

Enquanto não existir unidade entre prática e teoria e mesmo união entre os cidadãos, e obediências às normas e fundamentos, o direito de todos e para todos (equidade) estará à mercê do princípio da Isonomia (Tratar os Iguais como Iguais e os Diferentes como Diferentes).

\section{A educação básica pelo viés da Pedagogia e Filosofia}

De acordo com Libâneo, Oliveira e Toschi (2009, p. 326), a gestão democráticoparticipativa busca a combinação entre ênfase nas relações humanas, bem como a participação 
nas decisões para alcançar os objetivos propostos na escola, levando em consideração e valorizando elementos como: planejamento, organização, avaliação e direção.

“[...] a gestão participativa, além de ser a forma de exercício democrático da gestão e um direito da cidadania, implica deveres e responsabilidades - portanto a gestão da participação. Ou seja, a gestão democrática, por um lado, é a atividade coletiva que implica a participação e objetivos comuns; por outro, depende também de capacidades e responsabilidades individuais e de uma ação coordenada e controlada. (LIBÂNEO, OLIVEIRA E TOSCHI, 2009, p.326).

Podemos definir educação pré-escolar numa perspectiva mais ampla e integradora, em que educar e cuidar são funções que se articulam e complementam visando ao desenvolvimento de respostas educativas de qualidade previamente planificadas. A grande distância que ainda hoje existe entre o jardim de infância e a escola, entre educadores e profissionais de outros níveis de ensino, é dos obstáculos que dificultam que a educação préescolar seja efetivamente concebida como primeira etapa do sistema educativo.

A utilização da expressão educação pré-escolar, apesar das suas desvantagens, reforça o lugar deste tipo de educação a par dos restantes níveis de ensino. Excluem as crianças com idade inferior a 3 anos do sistema educativo, como já foi referido, 'pré-escolar' concebido de uma forma mais ampla, e inclui todas as crianças com idade inferior à da entrada na escola obrigatória.

Numa perspectiva educacional mais ampla, que não se esgota na preparação escolar, os educadores têm que ultrapassar a excessiva especificidade que os têm diferenciado, para que a educação pré-escolar ocupe efetivamente o seu lugar no sistema educativo.

A concepção da ética do cuidado, no sentido definido por Gilligan (1982), distanciando-se de uma lógica normativa de unicidade, traduzindo a sensibilidade às necessidades dos outros e o respeito pela sua individualidade, como sublinha Vasconcelos (2004), deve estar presente em qualquer nível de ensino, não sendo uma preocupação exclusiva da educação das crianças menores.

Se a pedagogia é relação, uma rede de compromissos e obrigações determinada pela nossa responsabilidade face ao Outro, então toda a relação pedagógica é uma relação ética. Não podemos falar de uma postura ética senão inserida num espaço semeado de relações humanas, nomeadamente em interação com pessoas que, em virtude da sua idade, são 
especialmente vulneráveis, exigindo uma ainda mais completa responsabilização e respeito pela sua autonomia e individualidade. (VASCONCELOS, 2004, p. 109-110).

Muitas das questões que têm afetado o desenvolvimento da educação pré-escolar, os dilemas que têm caracterizado a sua evolução e que ainda hoje se evidenciam nas práticas de trabalho, têm a ver com contradições na forma de conceber a infância, e as Nuances: estudos sobre Educação, Presidente Prudente, SP, v. 20, n. 21, p. 141-159, set./dez. 2011156 finalidades da sua educação. $\mathrm{O}$ direito dos pequenos a serem respeitados e considerados como cidadãos (LUC, 2010, p. 20) tem que ser efetivamente inspirador das políticas educativas desde o nascimento até a idade escolar.

\section{Considerações finais}

O desenvolvimento do presente estudo possibilitou uma análise sobre a educação básica brasileira, referenciando o contexto histórico, os principais artigos da Constituição e também sobre a obrigatoriedade do ensino básico.

Além disso, foram utilizados dados do Inep com apuração dos resultados mais consistentes sobre as etapas do processo de ensino como: a Creche e a Pré-escola, sua gratuidade e seu gerenciamento organizacional.

De um modo geral, ressaltou-se o Estado com a sua obrigatoriedade de fornecer a Educação básica e metodologicamente verificaram-se na Constituição Federal e no Estatuto da Criança e do Adolescente os direitos e garantias fundamentais.

Por sua vez, o questionário do Inep e os dados fornecidos foram de suma importância, pois mostram que nossa educação básica ainda engatinha rumo a um processo justo e igualitário.

Imprescindível perceber na Constituição Federal normas e direitos assegurados no que se refere à educação básica, porém, como promover no País dos processos lentos e morosos a agilidade e execução da Lei? Esta é uma tarefa árdua, vital e obrigatória e este estudo foi o início de uma discussão que, embora repetitiva, quase sempre se torna atual. Os direitos são garantias individuais e coletivas que devem ser seguidas, porque o essencial com efeito na educação não é a doutrina ensinada. E o despertar para uma consciência dos direitos 
Constitucionais é o ponto fundamental da formação de todo cidadão. Todos devem saber e conhecer seus direitos e garantias.

\section{Referências bibliográficas}

BRASIL. Constituição (1988). Constituição da República Federativa do Brasil. Brasília, DF: Senado Federal: Centro Gráfico, 1988.

BRASIL. Lei de Diretrizes e Bases da Educação Nacional. Lei n. ${ }^{\circ}$ 9.394, de 20 de dezembro de 1996. Estabelece as diretrizes e bases da educação nacional. Diário Ofícial da União, Brasília, DF, 23 dez. 1996. Disponível em: Acesso em: 23 abr. 2018.

BRASIL. Lei $\mathbf{n}^{0} \mathbf{8 . 0 6 9}$, de 13 de julho de 1990. Dispõe sobre o Estatuto da Criança e do Adolescente e dá outras providências. Disponível em: $<$ http://www.planalto.gov.br/ccivil_03/leis/18069.htm>. Acesso em: 15 dez. 2017.

BRASIL. Lei $\mathbf{n}^{0}$ 9.394, de 20 de dezembro de1996. Estabelece as diretrizes e bases da educação nacional. Disponível em: < http://www.planalto.gov.br/Ccivil_03/leis/L9394.htm>. Acesso em: 15 dez. 2017.

BRASIL. Ministério da Educação e Cultura. Publicações. 2017. Disponível em: $<$ http://portal.mec.gov.br/index.php?option=com_content\&view=article\&id=12598:publicaco es\&catid=195:seb-educacao-basica $>$. Acesso em: 23 fev. 2018.

CENSO ESCOLAR 2017. INEP - Instituto Nacional de Estudos e Pesquisas Educacionais Anísio Teixeira. Ministério da Educação. Disponível em: <http://www.censo.inep.gov.br/> . Acessado em: 28 fev. 2018.

GILLIGAN, C. Uma voz diferente. Rio de Janeiro: Rosa dos tempos, 1982

INEP. Notas Estatísticas do Censo Escolar, 2017- Inep.

LIBÂNEO, José Carlos, OLIVEIRA, João Ferreira de, TOSCHI, Mirza Seabra. Educação escolar: políticas, estrutura e organização. 7.ed. Cortez: São Paulo, 2009.

LUC, J-N. Les premières écolesenfantinesetl'inventiondujeune enfant. In: BECCHI, E. ; JULIA, D. (org.) Histoire de l'enfance em Occident. De l'Antiquitéau XVII éme Siècle. Tome 2. Paris : Èd. Seuil, 1996.

MENESES, João Gualberto de Carvalho. A profissão de professor e dos profissionais da Educação Básica. In: MENESES, João Gualberto de Carvalho et al. Estrutura e funcionamento da educação básica: leituras. 2. ed. São Paulo: Thomson learning, 1999, p. $291-299$. 
PERRENOUD, Philippe et al. A Escola de A a Z: 26 maneiras de repensar a Educação. Porto Alegre: Artmed, 2005.

RATZINGER, J. EI Dios de la fe y el Dios de los filósofos. Madrid: Encuentro, 2007.

Rel. Min. Celso de Mello, julgado em 12/05/2016 (Info 826).

VASCONCELOS, T. A educação de infância é uma ocupação ética. In: Revista Portuguesa de Pedagogia. Infância. Família, comunidade e educação, Coimbra: Faculdade de Psicologia e ciências da Educação da Universidade de Coimbra, Ano 38-1,2 e 3, p. 109-127, 2004. 